\title{
Density Determination of Ethyl Acetate-Palm Oil Mixture in Supercritical Condition
}

\author{
Cholada Komintarachat $^{1, \mathrm{a}}$, Ruengwit Sawangkeaw ${ }^{2, \mathrm{~b}}$, and , Somkiat Ngamprasertsith ${ }^{3,4, \mathrm{c}^{*}}$ \\ 1 Program in Petrochemistry, Faculty of Science, Chulalongkorn University, Phayathai Road, Pathumwan, \\ Bangkok 10330, Thailand \\ 2 The Institute of Biotechnology and Genetic Engineering, Chulalongkorn University, Institute Bldg. 3, 254 \\ Phayathai Rd., Pathumwan, Bangkok 10330, Thailand \\ 3 Fuels Research Center, Department of Chemical Technology, Faculty of Science, Chulalongkorn \\ University, Bangkok 10330, Thailand \\ 4 Center of Excellence on Petrochemical and Materials Technology, Chulalongkorn University, 254 \\ Phayathai Road, Pathumwan, Bangkok 10330, Thailand \\ E-mail: adachonla@gmail.com, brueangwit.s@chula.ac.th, csomkiat.n@chula.ac.th (Corresponding author)
}

\begin{abstract}
The non-catalytic interesterification of palm oil in supercritical ethyl acetate in continuous system to produce biofuel is complex to understand thermodynamic properties during extreme condition, particularly density of two reactants. In this study, an indirect procedure for density measurement of palm oil and ethyl acetate mixture in a batch system at high temperature and pressure was experimentally investigated using isochoric method. Its apparatus comprise a constant volume reactor which was individually loaded with a mixture of ethyl acetate and palm oil in different molar ratios (10:1 to 30:1) and global densities $\left(0.26\right.$ to $\left.0.53 \mathrm{~g} / \mathrm{cm}^{3}\right)$. During temperature increment, the changing of pressure was recorded in real-time to obtain the pressure-temperature relationship. After measuring the change of pressure at various global densities, the pressure-temperature related specific global density diagram was successfully constructed. At high global densities and high molar ratios of ethyl acetate to palm oil, the transition point took place closing to the estimated phase boundaries separating the region of vapor-liquid and homogenous phase of the mixture. The results will be further employed as database for accurate residence time calculation in continuous reactor, especially for biofuel production from palm oil in supercritical ethyl acetate.
\end{abstract}

Keywords: Biofuel, density, ethyl acetate, isochoric method, palm oil, supercritical condition.

ENGINEERING JOURNAL Volume 19 Issue 2

Received 15 June 2014

Accepted 5 November 2014

Published 30 April 2015

Online at http:/ / www.engj.org/

DOI:10.4186/ej.2015.19.2.29 


\section{Introduction}

Biodiesel is a renewable fuel which produced from triglyceride derived from vegetable oils and animal grease. The main reaction of biodiesel production is transesterification reaction between triglyceride and alcohol as illustrated in Fig 1. The alcohols commonly used in transesterification reaction are methanol and ethanol. However, methanol, widely employed as the reacting reagent due to its reasonable price and high reactivity, is commercially synthesized from natural gas. On the other hand, ethanol is alternatively produced by fermentation of agricultural biomass from renewable resources.<smiles>[R]C(=O)OCC(COC([R])=O)OC([R])=O</smiles>

Triglyceride

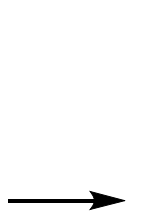<smiles>[R]C(=O)OCC</smiles><smiles>[R]C(=O)OCCC</smiles>

FAEE<smiles>OCC(O)CO</smiles>

Glycerol

Fig. 1. The transesterification reactions of palm oil (triglycerides) with ethanol.

A non-catalytic transesterification in the continuous system is beneficial in terms of high production efficiency, environmentally friendly process and feedstock flexibility over that of homogeneous catalytic process [1]. It has been developed to produce biodiesel from vegetable oils or animal fats in supercritical condition [2]. As the supercritical conditions provide solubility [3] between heterogeneous phases under the conditions that a liquid and its vapor become identical [4-6], reducing the mass transport limitation between phases and increasing the rate of reactions are simply removed [7]. However, the by-product glycerol may be excessive that poses an additional step in separation and purification.

Phase characteristics in the supercritical reactor during the homogeneous reaction depends on the reactants and reaction conditions [8]; many solvents can be chosen to operate the system in a single fluid phase. A systematic procedure to find solvents to achieve homogeneous conditions has been developed to produce biofuel [9-11]. One among other solvents, ethyl acetate is a carboxylate ester that can be used as supercritical solvent instead of alcohols in interesterification reaction [12], to obtain fatty acid ethyl ester (FAEE) or biofuel and triacetin following the reaction shown in Fig. 2. The ethyl acetate is synthesized from esterification of ethanol and acetic acid produced from renewable resources [13]. Typically, the triacetin is an additive to improve cold flow properties and pour point of biofuel [14].<smiles>[R]C(=O)OCC(COC([R])=O)OC([R])=O</smiles><smiles>[R]C(=O)OCCCOC([R])=O</smiles><smiles>COC(=O)CC1CC(=O)OCC1C(=O)OC</smiles>

Triglyceride Ethyl acetate

Fig. 2. The interesterification reaction of palm oil (triglycerides) with ethyl acetate.

Due to the complex theory of fluid mixtures, the studies of Economou [15] and You et al. [16] experimentally explored an understanding of the thermodynamic behavior of pure fluids, leading to the development of quantitative prediction methods [17]. Among thermodynamic properties describing variable state of condition such as pressure $(p)$, temperature $(T)$ and density $(\rho)$, the accurate measurement of fluid mixture density is the most difficult to measurement. Recently, Velez et al. [18, 19] measured the 
density of reacting mixtures between sunflower oil and supercritical alcohols by isochoric technique in the ranges of 553-618 $\mathrm{K}$ temperatures, $100-400 \mathrm{bar}$ pressures and $25-40$ alcohol to oil molar ratios. This technique is an attractive procedure for obtaining accurate densities and phase transitions using a close constant volume reactor with temperature and pressure monitoring. Palavra et al. [20] described the principles of the isochoric methods in the research review and determined the amount of fluid inside in the high pressure cell as well as fluid mixtures density measurement. The information obtained from these experiments are not only provided the variation of density with pressure and temperature for each reacting system composition, but also give the conditions in which the system transforms from heterogeneous phase to homogeneous phase [21].

To understand the relationship of temperature and pressure at a given global density, the indirect isochoric method has been proposed for this study. This is due to the fact that, at this condition, the combination of two substances in homogeneity is difficult to directly observe. Additionally, the temperature and pressure determination at constant global density by isochoric method is readily and convenient for mixture at supercritical conditions. In the system of this study, the vegetable oil is completely dissolved in ethyl acetate at atmospheric condition [22] that reduces mass transfer and solubility limitations [23]. The experimental results will show the variation of pressure versus temperature at constant composition of reacting mixture. The relationship of temperature, pressure and global density will be investigated and it can generate a diagram of temperature-pressure-global density individual reaction. It is thus possible to locate the boundaries between the vapor-liquid phase and homogeneous regions for the reacting systems.

\section{Experimental Section}

\subsection{Materials}

The compounds used in this experiment were ethyl acetate (99.97\% from Fisher Scientific) and palm olein oil (with a major fatty acid composition w/w of $37 \%$ palmitic, $46 \%$ oleic and $11 \%$ linoleic acids). The palm olein oil was obtained from Morakot Industries Co., Ltd.

\subsection{Apparatus and Procedures}

The measurement cell configuration is shown in Fig. 3 [18]. The global density of ethyl acetate and palm oil mixture was calculated from the known mixture weight divided by the cell volume. The dimension of the measurement cell made from SUS316 stainless steel are $0.95 \mathrm{~cm}$ outside diameter and $50 \mathrm{~cm}$ length with a working volume of $23 \mathrm{~cm}^{3}$ (by water substitution) at room temperature. A tubular furnace from Lenton, model 2416CG, was used as a heating source. This cell was insulated with ceramic fiber and aluminum foil to stabilize the inside temperature during the measurement. The pressure in the cell was measured by a high-temperature, tube and socket pressure gauge, model EN 837-1 from Fantinelli Srl with a $10 \mathrm{~cm}$ panel diameter.

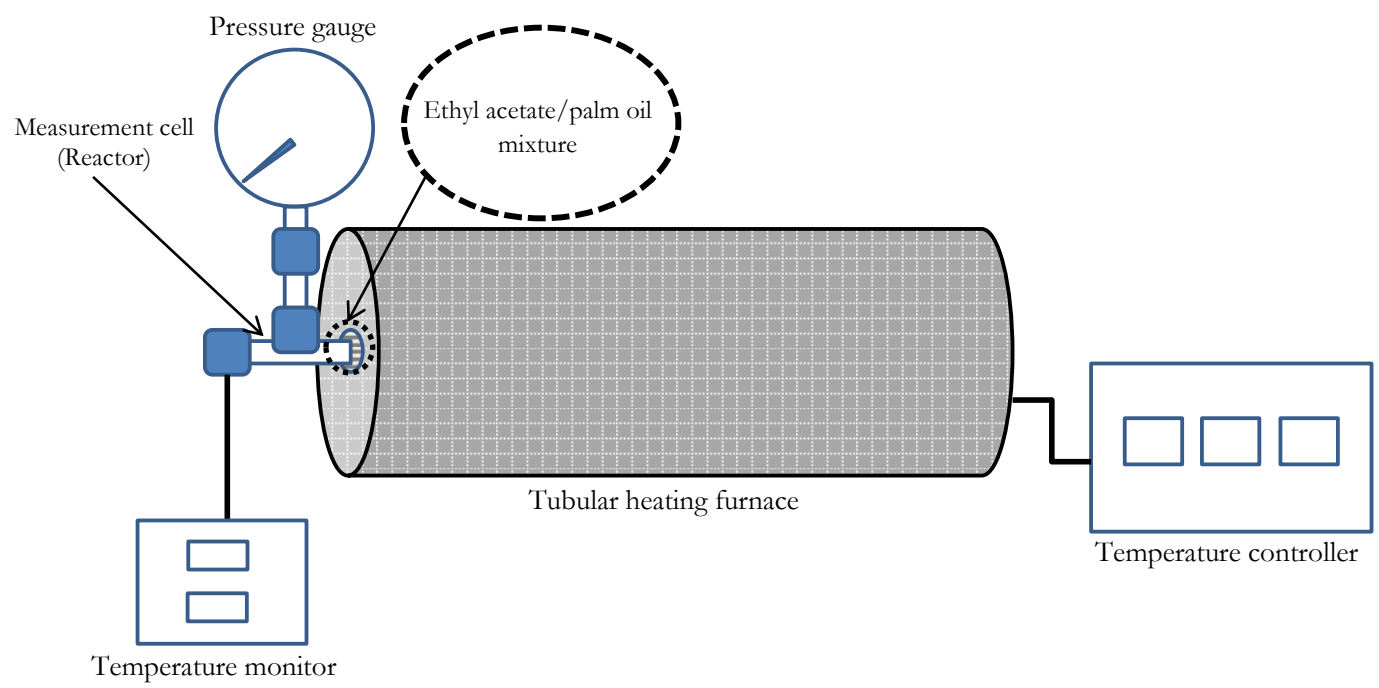

Fig. 3. Schematic diagram of experimental set-up. 
At the beginning, the predetermined masses of ethyl acetate and palm oil were added to the cell. The temperature was increased slowly at the rate of $5 \mathrm{~K} / \mathrm{min}$ from room temperature to $673 \mathrm{~K}$. During the temperature increment, both pressure and temperature were stabilized and recorded. In this way, the pressure variations with temperature of mixtures of a given mass charged into the cell were measured; the global density (mass charged divided by cell volume) was known for each run. This information provided the variation of one value of density with temperature and pressure over the range of $303 \mathrm{~K}$ to $673 \mathrm{~K}$ and $30 \mathrm{bar}$ to $150 \mathrm{bar}$. By repeating this procedure for different densities and reacting mixture compositions, the values of density over the range of conditions required were subsequently attained. To obtain precise transition points, all conditions were repeated for three times; repeatability and reproducibility can be achieved. In each condition, the results shown in later sections represent average values with error bars at 95\% confidence.

In order to accurately correlate the pressure measurement of the ethyl acetate-palm oil system, the experimental measurement values were compared with the data calculation from the Peng-Robinson equation of state (PR EOS) [24] for predicting the vapor pressure and phase behavior near the critical temperature of single-component system. The values of critical pressure and temperature as well as other key properties of the pure substances (palm oil and ethyl acetate) used in this study are listed in Table 1 [25, 26].

Table 1. Characteristics of pure compounds.

\begin{tabular}{lcccc}
\hline Substance & $\begin{array}{c}T \mathrm{c} \\
(\mathrm{K})\end{array}$ & $\begin{array}{c}P \mathrm{c} \\
(\mathrm{bar})\end{array}$ & $\begin{array}{c}M \mathrm{w} \\
(\mathrm{g} / \mathrm{mol})\end{array}$ & $\omega$ \\
\hline Palm oil [25] & 954.1 & 3.6 & 850.0 & 1.800 \\
Ethyl acetate [26] & 523 & 38.8 & 88.11 & 0.362 \\
\hline
\end{tabular}

\section{Results and Discussion}

\subsection{The p-V-T Relationship of Ethyl Acetate}

The pressures corresponding to the temperature of ethyl acetate obtained by experiment and calculation by the PR EOS in comparison are shown in Fig. 4 at the constant molar volume of $9.86 \times 10^{-4} \mathrm{~m}^{3} / \mathrm{mol}$. It has apparently shown that the measured data are in good agreement with those from the PR EOS, indicating that there is a potential for the further experimental results being acceptable.

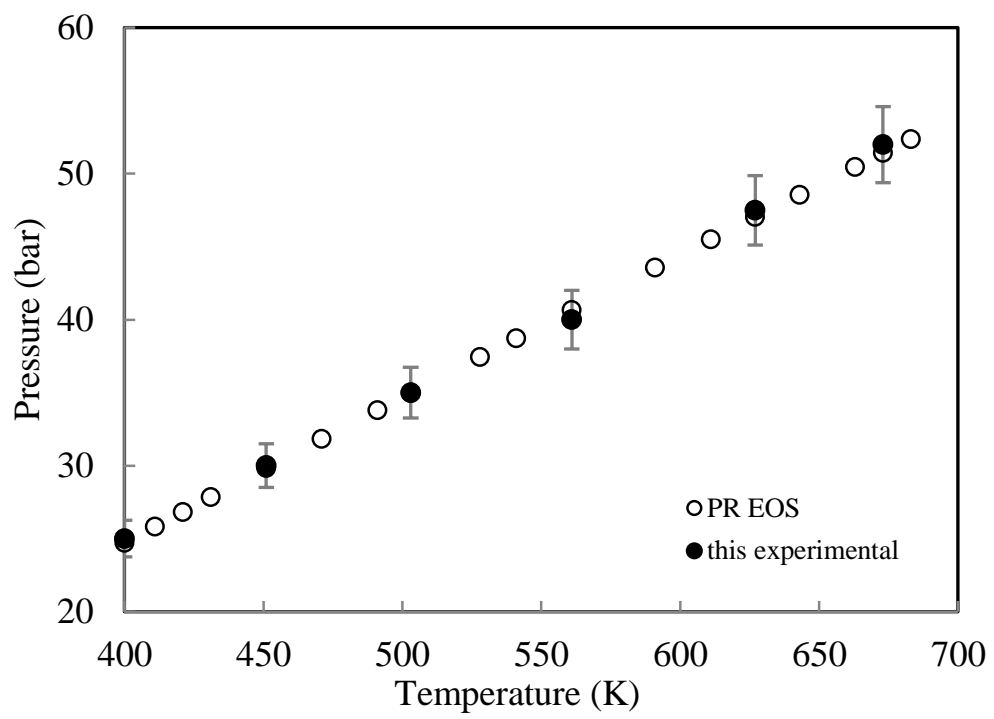

Fig. 4. Comparison of experimental data (O) for the ethyl acetate with predictions using the PengRobinson equation of state (PR EOS) and experimental $(\bullet)$. 


\subsection{The p-V-T Relationship of Ethyl Acetate-Palm Oil System}

In the constant volume reactor, the relationship of pressure and temperature at constant global density or molar volume was investigated. The information during the process generates P-T diagram as shown in Fig. 5. The discontinuity of slope of the isochoric line indicates phase transition point [27].

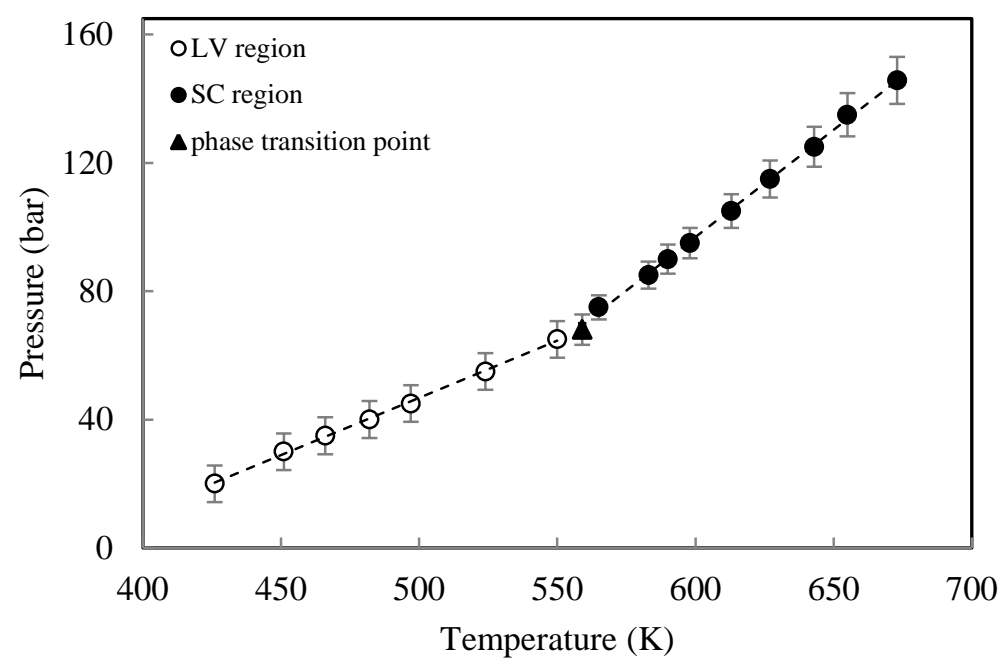

Fig. 5. Pressure vs. temperature for the reactive mixture of ethyl acetate:palm oil molar ratio of 20:1, global density $=0.44 \mathrm{~g} / \mathrm{cm}^{3}$.

The palm oil is completely miscible in ethyl acetate at ambient condition. After temperature increased the vapor-liquid (LV) region of ethyl acetate-palm oil mixture changes to supercritical (SC) fluid. The pressure-temperature curve consists of two sections with separated linear isochoric lines. The lower pressure-temperature line corresponds to the LV region of the mixture. In this range, the liquid phase of ethyl acetate-palm oil mixture forms mutual solubility system while the vapor phase is ethyl acetate rich phase. It is to note that the isochoric line of the mixture has a lower slope comparing to the vapor pressure line of pure ethyl acetate (Fig. 4) due to the low volatility of palm oil [28]. In Fig. 5, when the phase transition point was reached, the LV phase was transformed into vapor and the system performs as a single-phase supercritical fluid. It could be deduced that the mixture in the single phase region was a monophasic dense gas; the appearance of the phase boundaries must be, however, confirmed by conducting experiments in a high temperature and pressure view-cell [29] but this technique has both strength and limitation. Visual observation at the boundary between phases may sometimes be obscured or may be poor or absent [30]. In Fig. 5, phase transition point of the mixture was observed at $553 \mathrm{~K}$ and 66 bar where it is above the critical point of pure ethyl acetate. The phase transition points of ethyl acetatepalm oil systems at different compositions and global densities were tabulated in Table 2.

The phase transition points in Table 2 were assumingly observed as critical points of the mixture at different compositions. The mixtures have lower critical temperature than that of palm oil and slightly higher than that of ethyl acetate (see Table 1). As the mixtures contain ethyl acetate in greater proportion than palm oil, the critical temperature of mixture is close to that of ethyl acetate rather than palm oil.

\subsection{The Effect of Global Densities and Molar Ratio of Ethyl Acetate to Palm Oil}

The P-T diagram of molar ratio of ethyl acetate: palm oil and global densities varied from 0.26 to 0.53 $\mathrm{g} / \mathrm{cm}^{3}$ in this study are shown in Fig. 6. The slope of P-T diagram slightly changes at the individual phase transition point corresponding to its global density, except at the global density of $0.26 \mathrm{~g} / \mathrm{cm}^{3}$. In lower pressure (30-70 bar) and temperature $(400-560 \mathrm{~K})$ region, the mixture with a higher density generated a higer pressure. Within the SC region, the mixture that has higher global density simultaneously shifts the transition point to the lowered temperatures and pressures. The obtained results are in agreement with 
Hegel et al. [6] who reported that the phase transitions in a dense liquid phase depend mainly on the reactant concentration and global density.

Table 2. Phase transition points of ethyl acetate-palm oil systems at various conditions.

\begin{tabular}{cccc}
\hline \multirow{2}{*}{$\begin{array}{c}\text { Ethyl acetate:Oil } \\
\text { Molar ratio }\end{array}$} & $\begin{array}{c}\text { Global } \\
\text { density } \\
\left(\mathbf{g} / \mathbf{c m}^{3}\right)\end{array}$ & $\begin{array}{c}\text { Temperature } \\
(\mathbf{K})\end{array}$ & $\begin{array}{c}\text { Pressure } \\
(\mathbf{b a r})\end{array}$ \\
\hline $10: 1$ & 0.26 & - & - \\
& 0.35 & 572 & 74 \\
& 0.44 & 570 & 72 \\
& 0.53 & 559 & 67 \\
$20: 1$ & 0.26 & - & - \\
& 0.35 & 558 & 68 \\
& 0.44 & 553 & 66 \\
$30: 1$ & 0.53 & 549 & 61 \\
& 0.26 & - & - \\
& 0.35 & 541 & 61 \\
& 0.44 & 537 & 59 \\
& 0.53 & 533 & 57 \\
\hline
\end{tabular}

In the LV region in Fig. $6 \mathrm{a}-6 \mathrm{c}$ (left hand side of the phase transition point), the pressure-temperature slopes for all densities are nearly identical. Konynenburg and Scott [31] described the phase behavior of a binary mixture that the critical point of the mixture was located at where the density and composition of the two phases are assembling. Therefore, the critical points of ethyl acetate-palm oil mixture at different molar ratios in this study were predicted as phase transition points. It can also be seen in Fig. $6 \mathrm{a}-6 \mathrm{c}$ that at the density of $0.26 \mathrm{~g} / \mathrm{cm}^{3}$ of all the molar ratios of ethyl acetate to palm oil, there is no transition point, due to the density of the mixtures lower than the critical density of ethyl acetate $\left(0.308 \mathrm{~g} / \mathrm{cm}^{3}\right)$.

Velez et al. [19] determined the phase transition of sunflower oil and ethanol mixture in supercritical condition using isochoric method. Comparing to the palm oil/ethyl acetate mixture, the phase transition points of the two systems at constant global density of $0.44 \mathrm{~g} / \mathrm{cm}^{3}$ are shown in Table 3 . The phase transition point of the sunflower oil/ethanol mixture was significantly higher for temperature and pressure than this work. It can be presumed that the sunflower oil/ethanol mixture requires high temperature and pressure to transform heterogeneity towards homogeneity. It is to note that the higher molar ratio of ethanol to sunflower oil generates a rich vapour phase of ethanol, increasing the system temperature and pressure. In addition, the polarity of vegetable oil and reactant at room temperature affects the solubility of mixture and phase transition points in supercritical condition [32].

Table 3. Pressure and temperature at phase transition of a reacting system in supercritical reactor.

\begin{tabular}{ccccc}
\hline \multirow{2}{*}{ System } & \multicolumn{4}{c}{ Phase transition point } \\
\cline { 2 - 5 } & Molar ratic & $\begin{array}{c}\text { global density } \\
\mathbf{( g / \mathbf { c m } ^ { 3 } )}\end{array}$ & $\begin{array}{c}\text { Temperature } \\
\mathbf{( K )}\end{array}$ & $\begin{array}{c}\text { Pressure } \\
\mathbf{( b a r )}\end{array}$ \\
\hline Sunflower oil/ethanol [19] & $1: 40$ & 0.44 & 588 & 110 \\
Palm oil/ethyl acetate (this work) & $1: 30$ & 0.44 & 553 & 66 \\
\hline
\end{tabular}



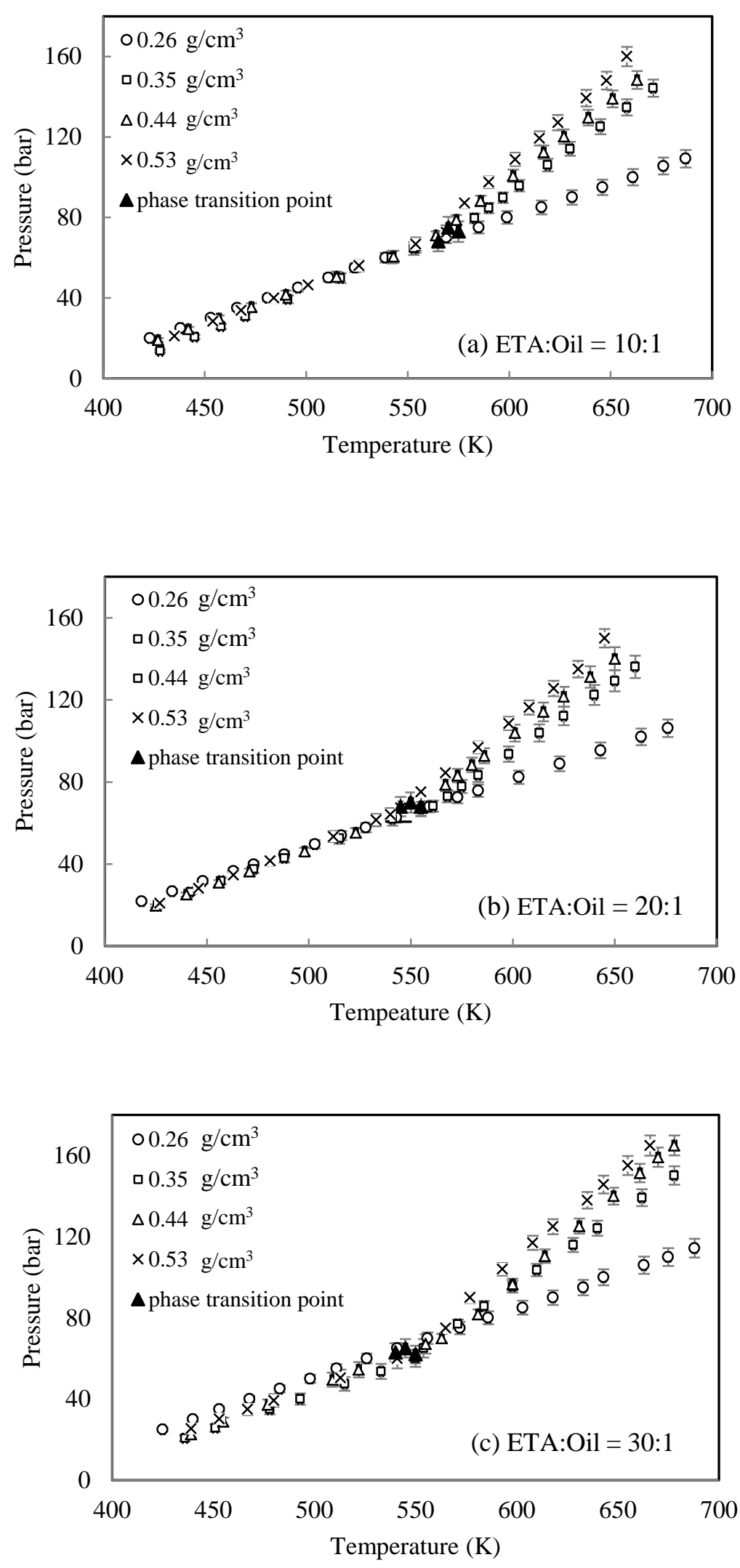

Fig. 6. Pressure vs. temperature of ethyl acetate and palm oil mixtures in molar ratio of (a) 10:1 (b) 20:1 and (c) 30:1 in different global densities (see Appendix for data). 


\section{Conclusions}

The density determination of ethyl acetate and palm oil system in supercritical condition has been accomplished in this work by indirect isochoric method. The molar ratio and global density of the mixture affected the LV region transformation to single phase of the mixture. The phase transition point from the LV region to SC region was also approximately located. The transition points were lowered by increasing global density and ethyl acetate: oil molar ratio. The subsequent data can be applied to find conditions of temperature and pressure that a homogeneous mixture of ethyl acetate and palm oil is optimized for producing biofuel in supercritical conditions.

\section{Acknowledgment}

The authors would like to thank the Program in Petrochemistry and Polymer Science of the Faculty of Science at Chulalongkorn University and the Ratchadaphiseksomphot Endowment Fund of Chulalongkorn University (RES560530071-EN) for financial support.

\section{References}

[1] R. Sawangkeaw, K. Bunyakiat, and S. Ngamprasertsith, "A review of laboratory-scale research on lipid conversion to biodiesel with supercritical methanol (2001-2009)," The Journal of Supercritical Fluids, vol. 55, pp. 1-13, 2010.

[2] K. Bunyakiat, S. Makmee, R. Sawangkeaw, and S. Ngamprasertsith, "Continuous Production of Biodiesel via Transesterification from Vegetable Oils in Supercritical Methanol," Energy \& Fuels, vol. 20, pp. 812-817, 2006.

[3] H. Sim Yeoh, G. Hean Chong, N. Mohd Azahan, R. Abdul Rahman, and T. S. Yaw Choong, "Solubility Measurement Method and Mathematical Modeling in Supercritical Fluids," Engineering Journal, vol. 17, pp. 67-78, 2013.

[4] T. Fang, Wahyudiono, B. Al-Duri, Y. Shimoyama, Y. Iwai, M. Sasaki, et al., "Supercritical Methanol Process of Modifying Oil Byproduct for Concentrating Natural Tocopherols," Industrial \& Engineering Chemistry Research, vol. 46, pp. 5325-5332, 2007.

[5] S. Glisic, O. Montoya, A. Orlovic, and D. Skala, "Vapor-liquid equilibria of triglycerides-methanol mixtures and their influence on the biodiesel synthesis under supercritical conditions of methanol," Journal of the Serbian Chemical Society, vol. 72, pp. 13-27, 2007.

[6] P. Hegel, G. Mabe, S. Pereda, and E. A. Brignole, "Phase Transitions in a Biodiesel Reactor Using Supercritical Methanol," Industrial \& Engineering Chemistry Research, vol. 46, pp. 6360-6365, 2007.

[7] S. Saka and D. Kusdiana, "Biodiesel fuel from rapeseed oil as prepared in supercritical methanol," Fuel, vol. 80, pp. 225-231, 2001.

[8] T. Pinnarat and P. E. Savage, "Assessment of Noncatalytic Biodiesel Synthesis Using Supercritical Reaction Conditions," Industrial \& Engineering Chemistry Research, vol. 47, pp. 6801-6808, 2008.

[9] S. Pereda, S. B. Bottini, and E. A. Brignole, "Supercritical fluids and phase behavior in heterogeneous gas-liquid catalytic reactions," Applied Catalysis A: General, vol. 281, pp. 129-137, 2005.

[10] R. Sawangkeaw, K. Bunyakiat, and S. Ngamprasertsith, "Effect of co-solvents on production of biodiesel via transesterification in supercritical methanol," Green Chemistry, vol. 9, p. 679, 2007.

[11] N. Jomtib, C. Prommuak, M. Goto, M. Sasaki, and A. Shotipruk, "Effect of Co-Solvents on Transesterification of Refined Palm Oil in Supercritical Methanol," Engineering Journal, vol. 15, pp. 4958, 2011.

[12] F. Goembira, K. Matsuura, and S. Saka, "Biodiesel production from rapeseed oil by various supercritical carboxylate esters," Fuel, vol. 97, pp. 373-378, 2012.

[13] B. Jorgensen, S. Egholmchristiansen, M. Dahlthomsen, and C. Christensen, "Aerobic oxidation of aqueous ethanol using heterogeneous gold catalysts: Efficient routes to acetic acid and ethyl acetate," Journal of Catalysis, vol. 251, pp. 332-337, 2007.

[14] A. Casas, J. R. n. Ruiz, M. a. J. s. Ramos, and A. n. Pérez, "Effects of Triacetin on Biodiesel Quality," Energy \& Fuels, vol. 24, pp. 4481-4489, 2010. 
[15] I. G. Economou, "Statistical Associating Fluid Theory: A Successful Model for the Calculation of Thermodynamic and Phase Equilibrium Properties of Complex Fluid Mixtures," Industrial \& Engineering Chemistry Research, vol. 41, pp. 953-962, 2002.

[16] S.-S. You, K.-P. Yoo, and C. S. Lee, "An approximate nonrandom lattice theory of fluids," Fluid Phase Equilibria, vol. 93, pp. 193-213, 1994.

[17] A. Fazlali, H. Modarress, and G. A. Monsoori, "Phase behavior prediction of complex petroleum fluids," Fluid Phase Equilibria, vol. 179, pp. 297-317, 2001.

[18] A. Velez, P. Hegel, G. Mabe, and E. A. Brignole, "Density and Conversion in Biodiesel Production with Supercritical Methanol," Industrial \& Engineering Chemistry Research, vol. 49, pp. 7666-7670, 2010.

[19] A. Velez, S. Pereda, and E. A. Brignole, "Isochoric lines and determination of phase transitions in supercritical reactors," The Joumal of Supercritical Fluids, vol. 55, pp. 643-647, 2010.

[20] A. M. F. Palavra, M. A. Tavares Cardoso, J. A. P. Coelho, and M. F. B. Mourato, "Density Measurements of Fluids and Their Mixtures at High Pressure," Chemical Engineering \& Tecbnology, vol. 30, pp. 689-694, 2007.

[21] M. Küster and B. Stijckhert, "Density changes of fluid inclusions in high-pressure low-temperature metamorphic rocks from crete: a thermobarometric approach based on the creep strength of the host minerals," Lithos, vol. 42, p. 17, 1997.

[22] M. K. Modi, J. R. Reddy, B. V. Rao, and R. B. Prasad, "Lipase-mediated conversion of vegetable oils into biodiesel using ethyl acetate as acyl acceptor," Bioresour Technol, vol. 98, pp. 1260-4, Apr 2007.

[23] I. De Marco, O. Knauer, F. Cice, A. Braeuer, and E. Reverchon, "Interactions of phase equilibria, jet fluid dynamics and mass transfer during supercritical antisolvent micronization: The influence of solvents," Chemical Engineering Journal, vol. 203, pp. 71-80, 2012.

[24] D. Y. Peng and D. B. Robinson, "A new two-constant equation of state," Industrial Engineering Chemistry Fundamentals, vol. 15, pp. 59-64, 1976.

[25] S.-A. Hong, J.-D. Kim, J. Kim, J. W. Kang, and I.-J. Kang, "Phase equilibria of palm oil, palm kernel oil, and oleic acid+supercritical carbon dioxide and modeling using Peng-Robinson EOS," Journal of Industrial and Engineering Chemistry, vol. 16, pp. 859-865, 2010.

[26] T. Hu, Z. Qin, G. Wang, X. Hou, and J. Wang, "Critical Properties of the Reacting Mixture in the Esterification of Acetic Acid with Ethanol," Journal of Chemical \& Engineering Data, vol. 49, pp. 1809_ 1814, 2004.

[27] M. Atilhan, J. Zhou, S. Ejaz, D. Cristancho, J. Holste, and K. R. Hall, "Phase Behavior Concerns for Multicomponent Natural Gas-Like Mixtures," in Proceedings of the 1st Annual Gas Processing Symposium, 2009.

[28] L. J. Florusse, T. Fornari, S. B. Bottini, and C. J. Peters, "Phase behavior of carbon dioxide-lowmolecular weight triglycerides binary systems: measurements and thermodynamic modeling," The Journal of Supercritical Fluids, vol. 31, pp. 123-132, 2004.

[29] R. M. Oag, P. J. King, C. J. Mellor, M. W. George, J. Ke, M. Poliakoff, V. K. Popov, and V. N. Bagratashvili, "Determining phase boundaries and vapour/liquid critical points in supercritical fluids: a multi-technique approach," The Journal of Supercritical Fluids, vol. 30, pp. 259-272, 2004.

[30] W. Mayer, S. Hoffmann, G. Meier, and I. Alig, "Critical fluctuations in a binary mixture of polyethylene glycol and polypropylene glycol studied by ultrasonic and light scattering experiments," Physical Review E, vol. 55, pp. 3102-3110, 1997.

[31] P. H. V. Konynenburg and R. L. Scott, "Critical Lines and Phase Equilibria in Binary Van Der Waals Mixtures," Philosophical Transactions of the Royal Society A: Mathematical, Physical and Engineering Sciences, vol. 298, pp. 495-540, 1980.

[32] J. M. Bernal, P. Lozano, E. Garcia-Verdugo, M. I. Burguete, G. Sanchez-Gomez, G. Lopez-Lopez, M. Pucheault, M. Vaultier, and S. V. Luis, "Supercritical synthesis of biodiesel," Molecules, vol. 17, pp. 8696-719, 2012. 


\section{Appendix}

Table A1. The experimental average data for temperature and pressure at molar ratio of ethyl acetate to palm oil of 10:1 and various global densities.

\begin{tabular}{|c|c|c|c|c|c|c|c|}
\hline \multicolumn{8}{|c|}{ Density of palm oil/ethyl acetate $\left(\mathrm{g} / \mathrm{cm}^{3}\right)$} \\
\hline 0.26 & & 0.3 & & 0.4 & & 0.5 & \\
\hline $\mathbf{T}$ & $\mathbf{P}$ & $\mathbf{T}$ & $\mathbf{P}$ & $\mathbf{T}$ & $\mathbf{P}$ & $\mathbf{T}$ & $\mathbf{P}$ \\
\hline$(\mathrm{K})$ & (bar) & $(\mathrm{K})$ & (bar) & $(\mathrm{K})$ & (bar) & $(\mathrm{K})$ & (bar) \\
\hline 423 & 20.0 & 445 & 20.6 & 427 & 20.0 & 435 & 21.1 \\
\hline 438 & 25.0 & 458 & 25.9 & 442 & 24.4 & 454 & 28.4 \\
\hline 453 & 30.0 & 470 & 30.8 & 457 & 29.8 & 468 & 33.8 \\
\hline 466 & 35.0 & 491 & 39.3 & 473 & 35.5 & 484 & 39.9 \\
\hline 481 & 40.0 & 517 & 49.9 & 490 & 41.6 & 501 & 46.4 \\
\hline 496 & 45.0 & 542 & 60.1 & 515 & 50.5 & 526 & 56.0 \\
\hline 511 & 50.0 & 553 & 64.6 & 543 & 60.5 & 554 & 66.8 \\
\hline 524 & 55.0 & 565 & 69.5 & 565 & 68.4 & 569 & 72.5 \\
\hline 539 & 60.0 & 583 & 79.6 & 564 & 71.0 & 578 & 87.1 \\
\hline 554 & 65.0 & 590 & 84.7 & 574 & 78.8 & 590 & 97.6 \\
\hline 569 & 70.0 & 597 & 89.9 & 586 & 88.2 & 603 & 108.9 \\
\hline 585 & 75.0 & 605 & 95.8 & 602 & 100.7 & 615 & 119.3 \\
\hline 599 & 80.0 & 619 & 106.1 & 617 & 112.4 & 624 & 127.1 \\
\hline 616 & 85.0 & 630 & 114.1 & 627 & 120.2 & 638 & 139.3 \\
\hline 631 & 90.0 & 645 & 125.2 & 639 & 129.6 & 648 & 148.0 \\
\hline 646 & 95.0 & 658 & 134.7 & 651 & 139.0 & 658 & 156.7 \\
\hline 661 & 100.0 & 671 & 144.3 & 663 & 148.3 & 658 & 160.0 \\
\hline
\end{tabular}

Table A2. The experimental average data for temperature and pressure at molar ratio of ethyl acetate to palm oil of 20:1 and various global densities.

\begin{tabular}{|c|c|c|c|c|c|c|c|}
\hline \multicolumn{8}{|c|}{ Density of palm oil-ethyl acetate $\left(\mathrm{g} / \mathrm{cm}^{3}\right)$} \\
\hline \multicolumn{2}{|c|}{0.26} & \multicolumn{2}{|c|}{0.35} & \multicolumn{2}{|c|}{0.44} & \multicolumn{2}{|c|}{0.53} \\
\hline $\mathbf{T}$ & $\mathbf{P}$ & $\mathbf{T}$ & $\mathbf{P}$ & $\mathbf{T}$ & $\mathbf{P}$ & $\mathbf{T}$ & $\mathbf{P}$ \\
\hline (K) & (bar) & (K) & (bar) & (K) & (bar) & (K) & (bar) \\
\hline 418 & 21.8 & 442 & 26.4 & 425 & 20.0 & 427 & 20.9 \\
\hline 433 & 26.7 & 457 & 31.8 & 440 & 25.1 & 446 & 28.1 \\
\hline 448 & 31.6 & 473 & 37.5 & 456 & 30.9 & 463 & 34.6 \\
\hline 463 & 36.5 & 488 & 42.9 & 471 & 36.4 & 481 & 41.5 \\
\hline 473 & 39.8 & 515 & 52.5 & 498 & 46.2 & 512 & 53.4 \\
\hline 488 & 44.7 & 541 & 61.9 & 523 & 55.3 & 533 & 61.4 \\
\hline 503 & 49.6 & 555 & 66.9 & 538 & 60.7 & 540 & 64.1 \\
\hline 516 & 53.9 & 561 & 68.2 & 567 & 78.7 & 545 & 67.3 \\
\hline 528 & 57.8 & 568 & 73.0 & 573 & 83.2 & 555 & 75.1 \\
\hline 543 & 62.7 & 575 & 77.8 & 580 & 88.3 & 567 & 84.4 \\
\hline 559 & 67.9 & 583 & 83.3 & 586 & 92.8 & 583 & 96.9 \\
\hline 573 & 72.5 & 598 & 93.6 & 601 & 103.8 & 598 & 108.5 \\
\hline 583 & 75.8 & 613 & 103.9 & 615 & 114.2 & 608 & 116.3 \\
\hline 603 & 82.3 & 625 & 112.1 & 625 & 121.6 & 620 & 125.6 \\
\hline 623 & 88.9 & 640 & 122.4 & 638 & 131.2 & 632 & 134.9 \\
\hline 643 & 95.4 & 650 & 129.3 & 650 & 140.0 & 645 & 150.0 \\
\hline
\end{tabular}


Table A3. The experimental average data for temperature and pressure at molar ratio of ethyl acetate to palm oil of 30:1 and various global densities.

\begin{tabular}{|c|c|c|c|c|c|c|c|}
\hline \multicolumn{8}{|c|}{ Density of palm oil-ethyl acetate $\left(\mathrm{g} / \mathrm{cm}^{3}\right)$} \\
\hline 0.26 & & 0.3 & & 0.4 & & 0.5 & \\
\hline $\mathbf{T}$ & $\mathbf{P}$ & $\mathbf{T}$ & $\mathbf{P}$ & $\mathbf{T}$ & $\mathbf{P}$ & $\mathbf{T}$ & $\mathbf{P}$ \\
\hline$(\mathbf{K})$ & (bar) & (K) & (bar) & (K) & (bar) & $(\mathrm{K})$ & (bar) \\
\hline 410 & 20.0 & 436 & 20.6 & 439 & 20.0 & 423 & 22.6 \\
\hline 425 & 25.0 & 451 & 25.7 & 455 & 25.4 & 439 & 28.8 \\
\hline 440 & 30.0 & 478 & 34.9 & 477 & 30.1 & 453 & 37.2 \\
\hline 453 & 35.0 & 493 & 40.0 & 509 & 34.9 & 467 & 49.5 \\
\hline 468 & 40.0 & 515 & 47.5 & 522 & 39.3 & 480 & 54.5 \\
\hline 483 & 45.0 & 533 & 53.6 & 541 & 50.5 & 513 & 61.8 \\
\hline 498 & 50.0 & 550 & 60.0 & 555 & 60.0 & 541 & 67.2 \\
\hline 511 & 55.0 & 565 & 75.0 & 563 & 75.0 & 565 & 70.0 \\
\hline 526 & 60.0 & 577 & 90.0 & 581 & 90.0 & 577 & 81.7 \\
\hline 541 & 65.0 & 593 & 104.0 & 598 & 104.0 & 593 & 96.5 \\
\hline 556 & 70.0 & 608 & 117.0 & 614 & 117.0 & 608 & 110.4 \\
\hline 572 & 75.0 & 618 & 125.0 & 631 & 125.0 & 618 & 125.2 \\
\hline 586 & 80.0 & 635 & 138.0 & 648 & 138.0 & 635 & 140.0 \\
\hline 603 & 85.0 & 643 & 145.7 & 661 & 145.7 & 643 & 151.3 \\
\hline 618 & 90.0 & 655 & 155.1 & 670 & 159.1 & 655 & 155.1 \\
\hline 633 & 95.0 & 666 & 164.9 & 678 & 165.0 & 666 & 164.9 \\
\hline
\end{tabular}


